\title{
Hidrolik Eyletimli Bir Kanatçık Yükleme Cihazının Dinamik Modellemesi ve Tümlevli Geri Adımlama Yöntemi Kullanılarak Denetimi
}

\section{Bülent ÖZKAN ${ }^{* 1}$}

1 Türkiye Bilimsel ve Teknolojik Araștırma Kurumu, Savunma Sanayii Araștırma ve Geliştirme Enstitüsü (TÜBİTAK SAGE), Ankara

(Alınıs / Received: 17.07.2016, Kabul / Accepted: 23.12.2016, Online Yayınlanma / Published Online: 02.05.2017)

Anahtar Kelimeler Kanatçlk yükleme cihazı, Kanatçık tahrik sistemi, Hidrolik eyletim, Geri adımlama, Denetim

Özet: Kanatçık yükleme cihazları, havacılık uygulamalarında kullanılan tahrik (eyletim) sistemleri üzerindeki harici yük etkisi benzetimlerini yapmak amaciyla geliștirilmektedir. Bahsedilen uygulamalarda, kanatçık tahrik sistemlerinin aerodinamik kuvvet ve momentler altındaki başarımları ele alınması gereken önemli hususlardan biridir. Göz önüne alınan azami kuvvet ve moment değerlerine bağlı olarak, kanatçık yükleme cihazları elektromekanik, hidrolik veya pnömatik eyletimli olabilmektedir. Bant genişliği gereksinimi, eyletim şekline karar vermedeki bir diğer belirleyici unsur olarak öne çıkmaktadır. Bu bağlamda, daha yüksek kuvvet ve moment oluşturma kapasitesi ve yüksek bant genişliği dolayısıyla hidrolik eyletim daha avantajlı bir seçenek olarak belirmektedir. Bu çalışmada, hidrolik eyletimli bir kanatçık yükleme cihazı için tümlevli geri adımlama yöntemi kullanılarak denetim sistemi tasarlanması hususu ele alınmaktadır.

\section{Dynamic Modeling and Control of a Hydraulic Fin Loading System Using Integral Backstepping Method}

\begin{tabular}{ll}
\hline Keywords & Abstract: Fin loading systems are utilized to simulate the effects \\
Fin loading & of the external inputs on actuation systems in aerial applications. \\
system, & In those systems, the performance of the fin actuation systems \\
Fin actuation & subject to aerodynamic force and moment effects is one of the \\
system, & major issues to be handled. Depending on the amount of the \\
Hydraulic & maximum force and torque values, the loading systems are in the \\
actuation, & type of electromechanically-, hydraulically-, or pneumatically- \\
Backstepping, & actuated. The bandwidth requirement is another determining \\
Control & factor in deciding on the type of the actuation. In this scene, the \\
& hydraulic actuation systems are more advantageous than the \\
& others because of their large force and moment execution \\
& capabilities as well as high bandwidth properties. In this study, \\
& the issue of designing a control system for a hydraulically- \\
& actuated fin loading system is investigated regarding the integral \\
& backstepping method.
\end{tabular}

*Sorumlu yazar: bulent.ozkan@tubitak.gov.tr 


\section{Introduction}

Performance of the fin actuation systems utilized in aerial vehicles is directly dependent on their achievement against aerodynamic effects acting on the actuation system through control surfaces. In order to guarantee their success, it is necessary that the related verification tests be completed prior to the field implementation.

In aerospace engineering, the aerodynamic effects acting on the control surfaces of the flying systems are called 'hinge moments'. For observing the influence of the hinge moment on the control surfaces, the force and moment execution systems called 'fin loading systems' are developed. In these systems, the actuation unit is constructed in electromechanical, hydraulic, or pneumatic type depending on the performance requirements. Especially for the situations in which the amplitude of the forces and moments to be applied to the considered fin actuation system is relatively high, the hydraulicallyactuated configurations are chosen. The opportunity for larger bandwidth values constitutes the other advantage of these kind of structures as well as their small size-to-power ratio characteristics [1].

In earlier studies, conventional control systems mainly based on PID (proportional plus integral plus derivative) controller are developed for hydraulic loading systems. However, it is observed that these schemes can not make the control of the loading systems as accurate as desired because the PIDtype control action is not sufficient to handle parameter uncertainties in the hydraulic system and also disturbing effects [2,3]. Regarding the nonlinear characteristics of the hydraulic systems as well, several robust control methods are utilized in the control of hydraulic loading systems as a remedy to the inconveniencies mentioned above [4].
Although it is not so common as normbased control approaches, one of those methods is the so-called 'backstepping control' which is a recursive control technique. Especially when certain parametric uncertainties such as those on hydraulic parameters and unknown disturbance effects originating from the external loads are in concern, the backstepping control is proposed as a viable solution [1]. Regarding the complex nonlinear mathematical models of the hydraulic systems under consideration, the backstepping control scheme can be built for position tracking control applications of hydraulic loading systems [5]. In order to increase the tracking performance of those systems, a disturbance observer is coupled with the backstepping control structure so as to estimate the disturbance including the friction and loading forces. The related experimental studies show that the suggested approach yield satisfactory results in accordance with the disturbance observer designed [6]. The preceding structure is enhanced by taking the parameter uncertainties into account in the disturbance observer. In the mentioned scheme, the 'extended' disturbance observer accounts the external perturbations and parameter uncertainties separately [7]. Further, the actuator disturbance is considered in addition to the friction and hydraulic flow nonlinearities and thus the nonlinearity level of the loading system is increased more. Having performed the relevant computer simulations and laboratory experiments, it is seen that the proposed backstepping control scheme satisfies the tracking performance requirements [8]. As shown in the literature, the backstepping control scheme is improved in an adaptive manner by estimating some unknown parameters in hydraulic model and then the algorithm is tested on a constructed setup [1-3]. Apart from controlled loading systems, the 
backstepping control method is applied this method is called 'backstepping' on passive torque control systems both analytically and experimentally in an adaptive manner. The preceding work is supported by means of a Takagi-Sugeno fuzzy logic algorithm [9]. In another static hydraulic loader implementation, a Lyapunov-based robust control algorithm including friction compensation is conducted with a convenient state observer [10].

In order to design a controller using the backstepping method, the dynamic equations of the system to be controlled should be expressed in the lowertriangular form. For example, if $x_{i}$ anf $f_{i}$ denote the ith state variable of a system and corresponding function $(\mathrm{i}=1,2$, and 3), respectively, and $u$ represents its control input, the dynamic equations of the system can be expressed in the lower triangular form as [11-13]

$$
\begin{aligned}
& \dot{x}_{1}=f_{1}\left(x_{1}, x_{2}\right) \\
& \dot{x}_{2}=f_{2}\left(x_{1}, x_{2}, x_{3}\right) \\
& \dot{x}_{3}=f_{3}\left(x_{1}, x_{2}, x_{3}, u\right)
\end{aligned}
$$

In this technique, each of the differential equations given above is stabilized with the following state variable as the control variable. Namely, at the first stage, $x_{2}$ is used as the control variable for the $x_{1}$ dynamics in equation (1). Then, $x_{3}$ serves as the control variable of the $x_{2}$ dynamics given in equation (2). After stabilizing the $x_{1}$ and $x_{2}$ dynamics in equations (1) and (2), the actual control input $u$ is determined from equation (3) as a function of $x_{1}, x_{2}$, and $x_{3}$. In each stage, the corresponding stabilizing control law is obtained using an appropriate method such as using a proper Lyapunov function. Since a stabilizing feedback control law is derived at each stage and then the process goes one step back until the actual control input is determined,

$[5,11,14]$

In this study, a control system based on the integral backstepping approach is proposed for hydraulically-actuated fin loading systems. Unlike most of the relevant studies on the control of the hydraulic or electro-hydraulic loading systems, the torque control problem is handled here instead of the position or speed control. Namely, almost all of control schemes on the hydraulic loading systems are based on the position tracking of the output elements or shafts of the actuators while the torque on the shaft is directly chosen as the control variable in the present work. Selecting hydraulic motors as the actuators of the system, the control signals are generated with regard of the backstepping control. Here, an extra integral action is added to the control scheme to nullify the steadystate errors of the control system unlike the classical backstepping method. Namely, having derived the equations of motion of the mentioned system, the control algorithm is established upon this model in a way compatible with the backstepping method including an integral action. Afterwards, the gains are obtained for the system with a classical PID-type controller. In the end of the relevant computer simulations, it is seen that the backstepping control gives more satisfactory results than its classical counterparts because of its robustness. Apart from their superior characteristics, the implementation difficulties of the integral backstepping approach on a physical system are also emphasized within the scope of the work.

\section{Dynamic Modeling of the System}

The schematic representation of the regarded hydraulic fin loading system is shown in Figure 1. As seen from the figure, the loading system consists of four identical hydraulic motors placed on a horizontal table at an angle of $90^{\circ}$. In this 
Method

configuration, the corresponding fin actuation system consisting of four control fins is mounted on the system in vertical position such that each of its fin connection rods matches one of the hydraulic motor. Then, the hydraulic motors exert torques representing the external aerodynamic effects, i.e. hinge moments, on the fin connection rods. While the fin actuation system is subjected to torques through its fin connection rods, it reacts by trying to rotate those rods by means of its control system. In this scheme, it is intended to see that the fin loading system is capable of rotating the fin connection rods even if they are under aerodynamic hinge moment effects. In the mentioned connections, it is assumed that couplings are used with a reduction ratio of $N$ $(\mathrm{N}>1)$.

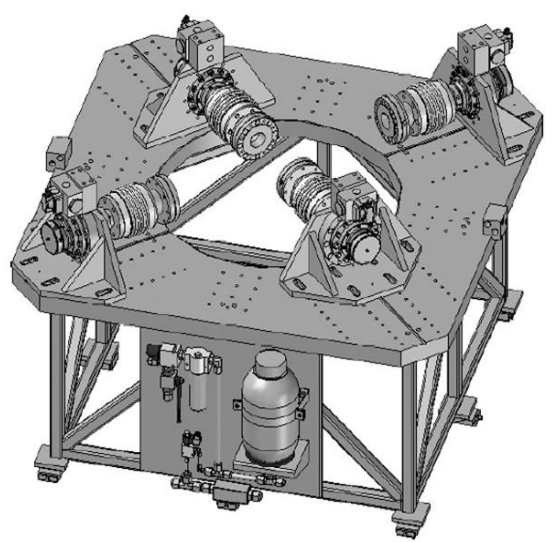

Figure 1. Hydraulic motor type fin loading system [15]

Regarding each fin-hydraulic motor connection, the hydraulic actuation system can be represented as in Figure 2.

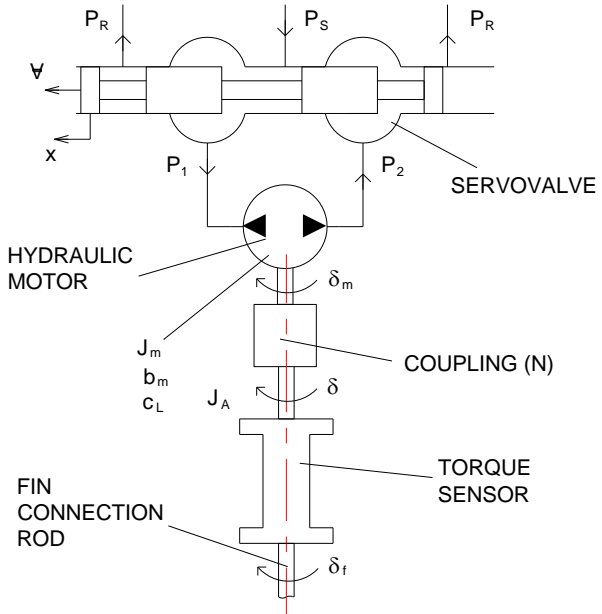

Figure 2. Hydraulic actuation system

As indicated in Figure 2, the actuation system is combined of a servovalve, a hydraulic motor, a coupling to make the connection between the motor and fin connection rod, and a torque sensor used to measure the net torque value on the motor output. In this configuration, the servovalve acts as a driver unit by allowing the amount of the pressurized hydraulic fluid proportional to the amount of the valve openings to pass through so as to rotate the hydraulic motor for getting the desired angular motion on its output shaft. The meanings of the symbols in Figure 2 are as listed below.

$b_{m}$ : Viscous friction coefficient between the rotary and stationary parts of the hydraulic motor

$c_{L}$ : Leakage coefficient between the separate volumes of the hydraulic motor $J_{m}$ and $J_{A}$ : Moment of inertia values of the rotary part of the hydraulic motor and half of the torque sensor with respect to their rotation axes, respectively

$N$ : Reduction ratio of the coupling $p_{1}$ and $p_{2}$ : Inlet and outlet pressures of the hydraulic motor, respectively $p_{R}$ and $p_{S}$ : Return and supply pressures on the inlet and outlet ports of the servovalve, respectively

$\forall$ : Control voltage to the position of the 
servovalve spool

$x$ : Displacement of the servovalve spool (valve opening)

$\delta_{m}$ : Angular displacement of the hydraulic motor output shaft

$\delta$ : Angular displacement of the coupling output shaft

$\delta$ : Angular displacement of the fin connection rod

Here, the servovalve dynamics can be expressed by the transfer function below using the Laplace variable ' $s$ ' in terms of the gain $\left(K_{v}\right)$ and time constant $\left(T_{v}\right)$ as the input and output variables are the displacement of servovalve control spool $(x)$ and servovalve control signal in voltage $(\forall)$ :

$$
\frac{x(s)}{\forall(s)}=\frac{K_{v}}{T_{v} s+1}
$$

The linearized servovalve characteristics can be described by the following formula in terms of the displacement of the servovalve control spool and load pressure $\left(p_{L}\right)[16]$ :

$$
Q_{L}=c_{X} x-c_{p} p_{L}
$$

where $Q_{L}, c_{X}$, and $c_{p}$ denote the volumetric flow rate of the load, servovalve displacement coefficient, and servovalve pressure coefficient, respectively. In this model, $Q_{L}$ is assumed as the mean flow rate of the flow rates in the inlet and outlet ports of the hydraulic motor. From Figure 2, $p_{L}$ is defined in the following manner [16]:

$$
p_{L}=p_{1}-p_{2}
$$

Thus, the load flow rate can be calculated using the expression below [16]:

$$
Q_{L}=D \dot{\delta}_{m}+[V /(2 \beta)] \dot{p}_{L}+c_{L} p_{L}
$$

where $D, \dot{\delta}_{m}, V$, and $\beta$ stand for the displacement of the hydraulic motor, i.e. the fluid volume per rotation handled by the rotary portion of the hydraulic motor, angular speed of the output shaft of the hydraulic motor, average volume of each part of the hydraulic motor, and bulk modulus, respectively.

The dynamics of the fin loading system is modeled regarding the next equation:

$$
J_{e} \ddot{\delta}+b_{m} \dot{\delta}+K_{s}\left(\delta-\delta_{f}\right)=D p_{L}
$$

where $J_{e}$ stands for the equivalent moment of inertia of the system on the output shaft of the coupling equal to $J_{m}+\left(J_{A} / N^{2}\right)$ while $K_{S}$ is the constant gain of the torque sensor.

Regarding Figure 2, the following equality is considered in the derivation of equation (8):

$$
\delta=\delta_{m} / N
$$

Since the control system under consideration handles the torque quantity on the fin connection rod as the control variable, $\delta_{f}$ can be assumed as a disturbance on the fin connecting rod. With this assumption, $p_{L}$ can be picked from equation (8) as follows:

$$
p_{L}=\left(J_{e} \ddot{\delta}+b_{m} \dot{\delta}+K_{s} \delta\right) / D
$$

The time derivative of equation (10) yields the following expression for a constant value of $D$ :

$$
\dot{p}_{L}=\left(J_{e} \dddot{\delta}+b_{m} \ddot{\delta}+K_{s} \dot{\delta}\right) / D
$$

Since the net displacement at the midpoint of the torque sensor is $\delta-\delta_{f}$, the torque value measured by the torque sensor $(T)$ can be found from the formula below: 
B. Özkan / Dynamic Modeling and Control of a Hydraulic Fin Loading System Using Integral Backstepping Method

$$
T=K_{s}\left(\delta-\delta_{f}\right)
$$

Accounting the same assumption that $\delta$ is the disturbance, equation (12) turns into the following form:

$$
T \approx K_{s} \delta
$$

From equation (13), $\delta$ can be found as a function of $T$ in the following fashion:

$$
\delta \approx T / K_{s}
$$

Hence, matching equations (5) and (7) and substituting equations (4), (10), and (11) into the resulting expression, the forthcoming differential equation comes into the picture in terms of $T$ along with the insertion of equation (14) and its successive time derivatives:

$$
d_{3} \dddot{T}+d_{2} \ddot{T}+d_{1} \dot{T}+d_{0} T=\forall
$$

where

$d_{0}=\frac{c_{L}+c_{p}}{c_{X} K_{v} D}$

$d_{1}=\frac{1}{c_{X} K_{v} D K_{s}}\left[\left(c_{L}+c_{p}\right) b_{m}+\frac{V K_{s}}{2 \beta}+D^{2} N\right]$

$d_{2}=\frac{1}{c_{X} K_{v} D K_{s}}\left[\left(c_{L}+c_{p}\right) J_{e}+\frac{V b_{m}}{2 \beta}\right]$ and

$d_{3}=\frac{V J_{e}}{2 \beta c_{x} K_{v} D K_{s}}$.

Considering that the ratio $V /(2 \beta)$ is much smaller than the other multipliers given in equation (7) and hence ignoring that division, equation (15) can be simplified to the following second-order expression:

$$
c_{2} \ddot{T}+c_{1} \dot{T}+c_{0} T=\forall
$$

where $\quad c_{0}=d_{0}, \quad c_{1}=\frac{\left(c_{L}+c_{p}\right) b_{m}+D^{2} N}{c_{X} K_{v} D K_{s}}$, and $c_{2}=\frac{\left(c_{L}+c_{p}\right) J_{e}}{c_{X} K_{v} D K_{s}}$.

\section{Design of the Control System \\ 3.1. Integral backstepping control}

As $T_{d}$ and $G_{c}$ denote the desired, or reference, value of $T$ and transfer function of the controller unit, the block diagram of the entire control system can be drawn as shown in Figure 3.

In order to apply the backstepping method to the present system, it is more appropriate to express the system dynamics in state space form. Regarding this fact, $T$ and its first time derivative $(\dot{T})$ can be selected to be the first and second state variables of the system as $x_{1}=T$ and $x_{2}=\dot{x}_{1}=\dot{T}$. Moreover, the time integration of $x_{1}$, i.e. $x_{0}=\int x_{1} d t$, is added to the control scheme as the additional state variable. Hence, the state equations of the fin loading system happen to be in the following fashion accounting equation (16) as well [17]:

$$
\begin{aligned}
& \dot{x}_{0}=x_{1} \\
& \dot{x}_{1}=x_{2}
\end{aligned}
$$

$$
\dot{x}_{2}=-\alpha_{1} x_{1}-\alpha_{2} x_{2}+\alpha_{u} u
$$

where $\alpha_{1}=c_{0} / c_{2}, \quad \alpha_{2}=c_{1} / c_{2}, \quad$ and $\alpha_{u}=1 / c_{2}$. 


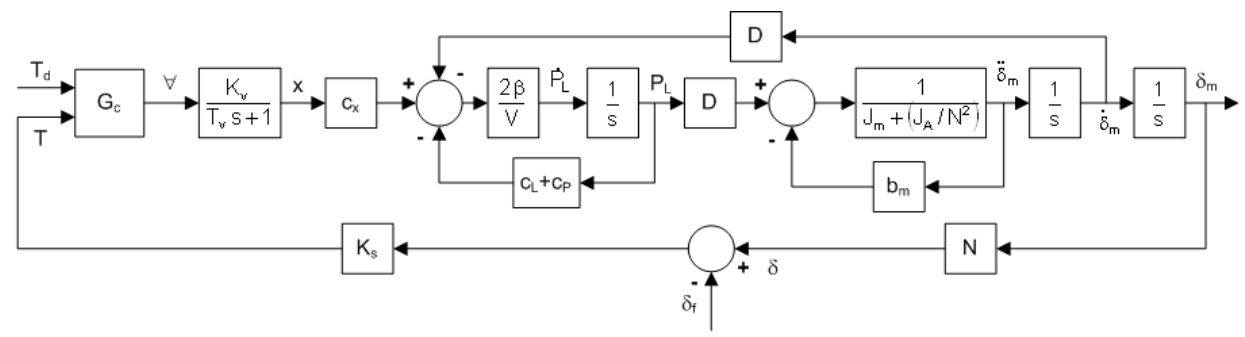

Figure 3. Block diagram of the control system

Looking at equations (17) through (19), it is seen that they are in the lower triangular form as explained using equations (1) through (3). Hence, the backstepping method can be applied to the system to construct a torque control system. From here, as subscript ' $d$ ' indicates the desired value of the corresponding variable, the error terms $\left(e_{i}\right)$ and relevant Lyapunov functions based on the state errors for each of the state variables $\left(V_{i}\right)$ can be constructed as in the following expressions for $\mathrm{i}=1$ and 2 [18-19]:

$$
\begin{aligned}
& e_{i}=x_{i d}-x_{i} \\
& V_{i}=V_{i-1}+(1 / 2) e_{i}^{2}
\end{aligned}
$$

where $V_{0}=(1 / 2) e_{0}^{2}$.

In designing a torque control system using the backstepping method with an integrator, the first step is the determination of the virtual control input $x_{1 d}$ which stabilizes $x_{0}$ dynamic given in equation (17). Here, the primary requirement on $x_{1 d}$ is that it should make $V_{0}$ strictly positive while the time derivative of $V_{0}\left(\dot{V}_{0}\right)$ has to be negative. To do this, the time derivative of $V_{0}$ is taken as given below:

$$
\dot{V}_{0}=-k_{0} e_{0}^{2}+e_{0} e_{1}
$$

In equation (22), the controller gain $k_{0}$ is defined as a positive constant in the following manner:

$$
k_{0}=\left(x_{1 d}-\dot{x}_{0 d}\right) / e_{0}
$$

Considering the selection given in equation (23), $x_{1 d}$ is obtained as

$$
x_{1 d}=\dot{x}_{0 d}+k_{0} e_{0}
$$

After determining $x_{1 d}$, the second step arises as the computation of the other virtual control input $x_{2 d}$. In the similar manner, $x_{2 d}$ can be found regarding the positive controller gain $k_{1}$ that is selected to make $\dot{V}_{1}$ negative as shown in equation (27). The resulting expressions for $\dot{V}_{1}$ and $k_{1}$ are also submitted in equations (25) and (26), respectively.

$\dot{V}_{1}=-k_{0} e_{0}^{2}-k_{1} e_{1}^{2}+e_{1} e_{2}$

$k_{1}=\left(x_{2 d}-\ddot{x}_{0 d}-k_{0} \dot{e}_{0}-e_{0}\right) / e_{1}$

$x_{2 d}=\ddot{x}_{0 d}+k_{0} \dot{e}_{0}+e_{0}+k_{1} e_{1}$

Finally, the real control input $u$ results from the expression written for $\dot{V}_{2}$ given in equation (28) with the definition of the positive controller gain $k_{2}$ as in equation (29):

$$
\begin{aligned}
\dot{V}_{2}=-k_{0} e_{0}^{2}-k_{1} e_{1}^{2}-k_{2} e_{2}^{2} & \\
u=\left(\dddot{x}_{0 d}\right. & +K_{2} \ddot{e}_{0}+K_{1} \dot{e}_{0}+K_{0} e_{0} \\
& \left.+\alpha_{1} x_{1}+\alpha_{2} x_{2}\right) / \alpha_{u}
\end{aligned}
$$

where $\quad K_{0}=k_{0}+k_{2}+k_{0} k_{1} k_{2}$, $K_{1}=k_{0} k_{1}+k_{0} k_{2}+k_{1} k_{2}+2, \quad$ and 
$K_{2}=k_{0}+k_{1}+k_{2}$

The compound controller gains $K_{0}, K_{1}$, and $K_{2}$ can be determined using the equations belonging to the error dynamics of the system. In this sense, the mentioned equations are revealed from the time derivatives of $e_{j}$ terms $(\mathrm{j}=0,1$, and 2) as listed below:

$$
\begin{aligned}
& \dot{e}_{0}=-k_{0} e_{0}+e_{1} \\
& \dot{e}_{1}=-e_{0}-k_{1} e_{1}+e_{2} \\
& \dot{e}_{2}=-e_{1}-k_{2} e_{2}
\end{aligned}
$$

The equations within (30) through (32) can be expressed more compactly in state space form in the following manner:

$$
\dot{\bar{e}}=\hat{K} \bar{e}
$$

$$
\begin{aligned}
& \text { where } \quad \bar{e}=\left[\begin{array}{lll}
e_{0} & e_{1} & e_{2}
\end{array}\right]^{T} \quad \text { and } \\
& \hat{K}=\left[\begin{array}{ccc}
-k_{0} & 1 & 0 \\
-1 & -k_{1} & 1 \\
0 & -1 & -k_{2}
\end{array}\right] .
\end{aligned}
$$

Having applied the Laplace transformation to the matrix equation (33), the equation giving the eigenvalues of the system appears to be as follows [17]:

$$
D(s)=s^{3}+K_{2} s^{2}+K_{1} s+K_{0}=0
$$

The form of $D(s)$ normalized to its constant term $\left[D^{\prime}(s)\right]$ becomes as

$$
\begin{aligned}
D^{\prime}(s)=\left(\frac{1}{K_{0}}\right) s^{3} & +\left(\frac{K_{2}}{K_{0}}\right) s^{2} \\
& +\left(\frac{K_{1}}{K_{0}}\right) s+1
\end{aligned}
$$

In order to determine the gains $K_{0}, K_{1}$, and $K_{2}$, the well-known pole placement technique can be used [17]. For this purpose, the next normalized third-order polynomial $D_{3}^{\prime}(s)$ corresponding to the characteristic polynomial of a thirdorder system dynamics is one of the appropriate candidates [20]:

$$
\begin{aligned}
D_{3}^{\prime}(s)=\left(\frac{1}{\omega_{c}^{3}}\right) s^{3} & +\left(\frac{2 \zeta_{c}+1}{\omega_{c}^{2}}\right) s^{2} \\
& +\left(\frac{2 \zeta_{c}+1}{\omega_{c}}\right) s+1
\end{aligned}
$$

where $\omega_{c}$ and $\zeta_{c}$ stand for the desired bandwidth, i.e. corner frequency, and damping ratio values of the constructed control system, respectively.

Specifying $\omega_{c}$ and $\zeta_{c}$ in accordance with the expected system performance, $K_{0}, K_{1}$, and $K_{2}$ are obtained as given below by equating $D^{\prime}(s)$ and $D_{3}^{\prime}(s)$ polynomials in equations (35) and (36) each other:

$$
\begin{aligned}
& K_{0}=\omega_{c}^{3} \\
& K_{1}=\left(2 \zeta_{c}+1\right) \omega_{c}^{2} \\
& K_{2}=\left(2 \zeta_{c}+1\right) \omega_{c}
\end{aligned}
$$

\subsection{Classical PID-type control}

The transfer function of from $\forall$ to $T$ can be obtained from equation (16) as follows:

$$
G(s)=\frac{T(s)}{\forall(s)}=\frac{1}{c_{2} s^{2}+c_{1} s+c_{0}}
$$

Taking $\delta_{f}$ as the external disturbance, the simplified block diagram of the classical control system is drawn for unity feedback as shown in Figure 4. 

Method

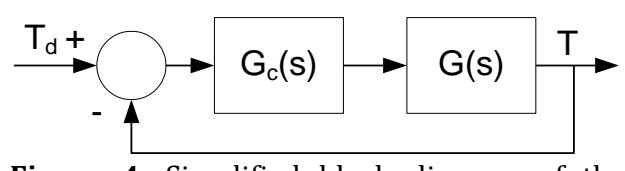

Figure 4. Simplified block diagram of the control system

Here, the controller transfer function $\left[G_{c}(s)\right]$ is equal to the next expression for the PID-type controller as $K_{p}, K_{i}$, and $K_{d}$ denote the proportional, integral, and derivative gains of the controller, respectively:

$$
G_{c}(s)=K_{p}+\frac{K_{i}}{s}+K_{d} s
$$

Considering equations (40) and (41), the overall transfer function of the closedloop control system becomes as given below:

$$
\frac{T(s)}{T_{d}(s)}=\frac{\left(\frac{K_{d}}{K_{i}}\right) s^{2}+\left(\frac{K_{p}}{K_{i}}\right) s+1}{D(s)}
$$

where

$$
\begin{aligned}
D(s)=\left(\frac{c_{2}}{K_{i}}\right) s^{3}+ & \left(\frac{c_{1}+K_{d}}{K_{i}}\right) s^{2} \\
& +\left(\frac{c_{0}+K_{p}}{K_{i}}\right) s+1
\end{aligned}
$$

As done for the case with the integral backstepping control, the controller gains can be determined by equating the $D^{\prime}(s)$ polynomial in equation (36) to the characteristic polynomial, i.e. denominator polynomial, of the transfer function of the closed-loop system in equation (42) represented by $D(s)$. Hence, $K_{p}, K_{i}$, and $K_{d}$ come into the picture in the following fashion:

$$
K_{p}=\left(2 \zeta_{c}+1\right) c_{2} \omega_{c}^{2}-c_{0}
$$

$$
\begin{aligned}
& K_{i}=c_{2} \omega_{c}^{3} \\
& K_{d}=\left(2 \zeta_{c}+1\right) c_{2} \omega_{c}-c_{1}
\end{aligned}
$$

\section{Computer Simulations}

In order to compare the performance characteristics of the integral backstepping- and PID-based control systems, the relevant models are constructed in the MATLAB ${ }^{\circledR}$ SIMULINK $^{\circledR}$ environment as shown in Figure 5.

Here, the comparison between the integral backstepping- and PID-based control systems are performed according to three criteria:

i. Maximum overshoot,

ii. Phase difference between the reference input and system output,

iii. Integral square error (ISE).

In this scene, it is regarded that the excessive amount of the hinge moment on the fin connection rod may cause it to break down during the operation. Also, it enforces the opposing fin actuation system to operate against excessive external torque and hence the fin actuation system may fail due to harder operating conditions. For this reason, the maximum overshoot is chosen as one of the comparison criteria for the cases in which the reference input is selected to be a step input. Apart from this, the phase difference between the reference input and system outputs values yielded by the control systems exists in certain cases. Thus, the phase difference is selected to be the second comparison factor.

For a fair comparison among different control systems, the use of ISE is a common practice in control engineering. In this study, ISE which constitutes the third comparison metric is calculated regarding the following equation [21]: 
B. Özkan / Dynamic Modeling and Control of a Hydraulic Fin Loading System Using Integral Backstepping Method

$$
I S E=\int_{t_{0}}^{t_{f}} e^{2}(t) d t
$$

where $t_{0}$ anf $t_{f}$ stand for the initial and final time values of the simulation considered, respectively. Also, the actuating error $[e(t)]$ is defined as follows:

$$
e(t)=e=T_{d}-T
$$

Since the hinge moment varies in magnitude similar to a harmonic function as a function of time in practice, it is evaluated to be more representative to apply sinusoidal test inputs to the system. Thus, $T_{d}$ and $\delta_{f}$ are applied in the form of sinusoidal functions as $T_{d}=T_{d 0} \sin \left(2 \pi f_{d}+\phi_{d}\right) \quad$ and $\delta_{f}=\delta_{f 0} \sin \left(2 \pi f_{d}\right) \quad$ with $\quad T_{d 0}=50 \quad \mathrm{~N} \cdot \mathrm{m}$, $\phi_{d}=\pi / 2 \mathrm{rad}, \delta_{f 0}=0.175 \mathrm{rad}\left(=10^{\circ}\right)$, and $\pi=3.14$. Here, $f_{d}$ is called the input frequency. Since the fin connection rod is desired to be subjected to an initial loading at an amount of $T_{d 0}$ as per an application requirement, the assignment of $\phi_{d}=\pi / 2 \mathrm{rad}$ is made. In the considered situations, 5, 15, and $25 \mathrm{~Hz}$ values are considered for $f_{d}$ to see the effectiveness of the proposed control schemes for sinusoidal reference. Moreover, the step response characteristics of both of the control systems are checked for comparison with a step height of $T_{d 0}=50 \mathrm{~N} \cdot \mathrm{m}$ and $f_{d}=5 \mathrm{~Hz}$. In all of the simulations, the friction nonlinearity is also taken into account as a randomlyvarying disturbance with a maximum value of $10 \mathrm{~N} \cdot \mathrm{m}$. The situations in which $J_{e}$ and $b_{m}$ parameters have $20 \%$ uncertainty are also simulated in addition to the cases based on nominal system parameters. The numerical values of the other relevant system parameters are presented in Table 1 . The $\omega_{c}$ value is selected in a manner consistent with similar realistic systems.

Performing the computer simulations under the conditions explained above, the torque responses of both the integral backstepping-based and PID-type control systems to the designated $T_{d}$ quantity are demonstrated in plots between Figure 8 and Figure 13 regarding all the situations taken into account. The data acquired from all relevant simulations in accordance with the considered performance criteria are given in Table 2 and Table 3 for the step and sinusoidal reference inputs, respectively. In these tables, the integral backstepping- and PID-based control systems are accounted under nominal and uncertain conditions for the considered system parameters.

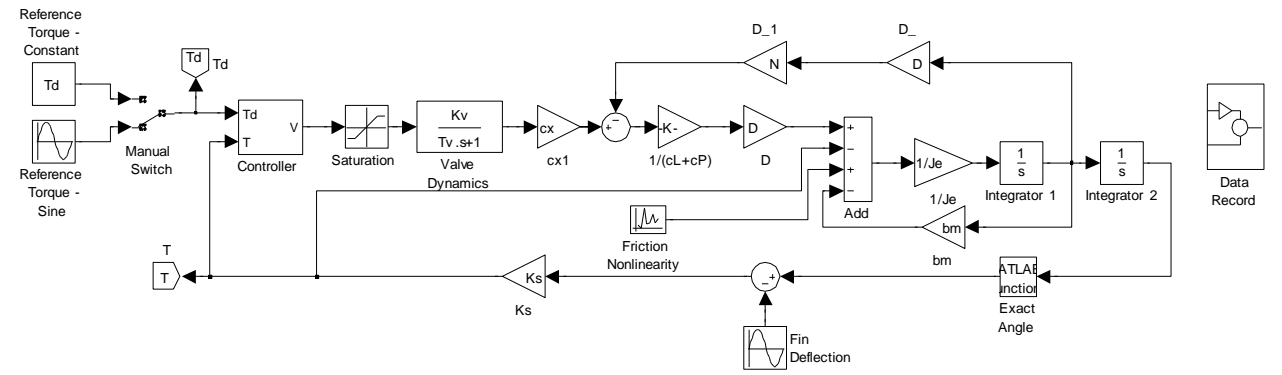

Figure 5. MATLAB ${ }^{\circledR}$ SIMULINK $^{\circledR}$ model of the fin loading system 
B. Özkan / Dynamic Modeling and Control of a Hydraulic Fin Loading System Using Integral Backstepping Method

Table 1. Numerical values of the relevant control system parameters used in the computer simulations

\begin{tabular}{cccc}
\hline Parameter & Numerical Value & Parameter & Numerical Value \\
$K_{v}$ & $5 \times 10^{-5} \mathrm{~m} / \mathrm{V}$ & $J_{e}$ & $1.5 \times 10^{-3} \mathrm{~kg} \cdot \mathrm{m}^{2}$ \\
$T_{v}$ & $4 \times 10^{-5} \mathrm{~s}$ & $b_{m}$ & $4 \times 10^{-3} \mathrm{~N} \cdot \mathrm{m} \cdot \mathrm{s} / \mathrm{rad}$ \\
$c_{X}$ & $0.7 \mathrm{~m}^{2} / \mathrm{s}$ & $N$ & 1.5 \\
$c_{p}$ & $1.5 \times 10^{-6} \mathrm{~m}^{3} /(\mathrm{Pa} \cdot \mathrm{s})$ & $K_{s}$ & $100 \mathrm{~N} \cdot \mathrm{m} / \mathrm{rad}$ \\
$D$ & $5 \times 10^{-4} \mathrm{~m}^{3} / \mathrm{rev}$ & $\omega_{c}$ & $157 \mathrm{rad} / \mathrm{s}=25 \mathrm{~Hz})$ \\
$V$ & $7 \times 10^{-5} \mathrm{~m} 3$ & $\zeta_{c}$ & 0.85 \\
$\beta$ & $7 \times 10^{8} \mathrm{~Pa}$ & $t_{0}$ & 0 \\
$c_{L}$ & $8 \times 10^{-10} \mathrm{~m}^{3} /(\mathrm{Pa} \cdot \mathrm{s})$ & $t_{f}$ & $0.35 \mathrm{~s}$ \\
\hline
\end{tabular}
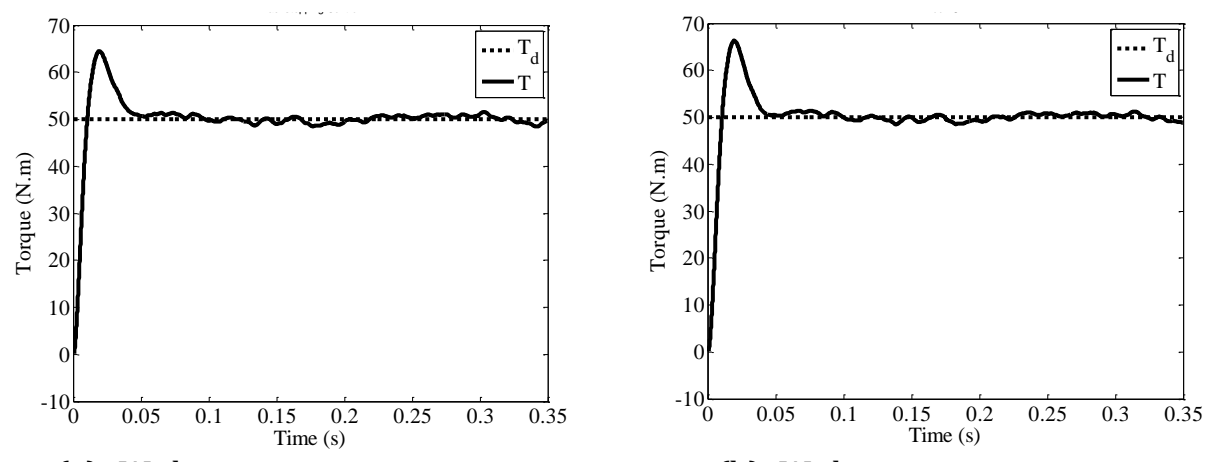

(a) Without parameter uncertainty

(b) With parameter uncertainty Figure 6. Response of the integral backstepping-based control system against step reference input for $f_{d}=5 \mathrm{~Hz}$

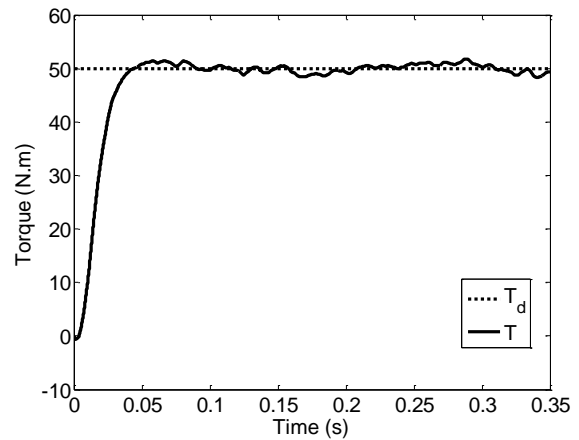

(a) Without parameter uncertainty

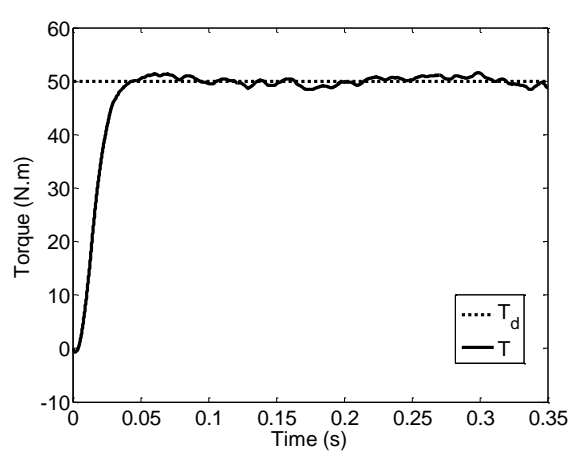

(b) With parameter uncertainty

Figure 7. Response of the PID-based control system against step reference input for $f_{d}=5 \mathrm{~Hz}$ 
B. Özkan / Dynamic Modeling and Control of a Hydraulic Fin Loading System Using Integral Backstepping Method

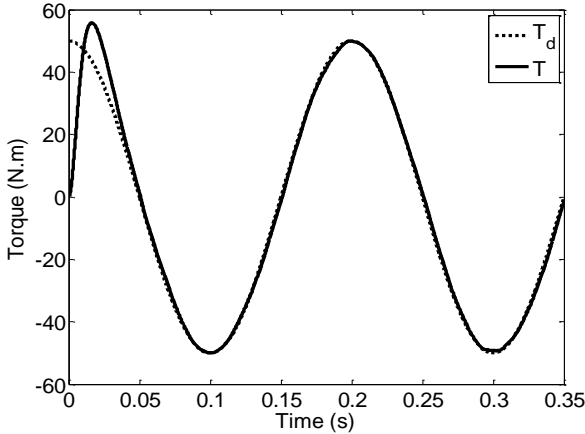

(a) Without parameter uncertainty

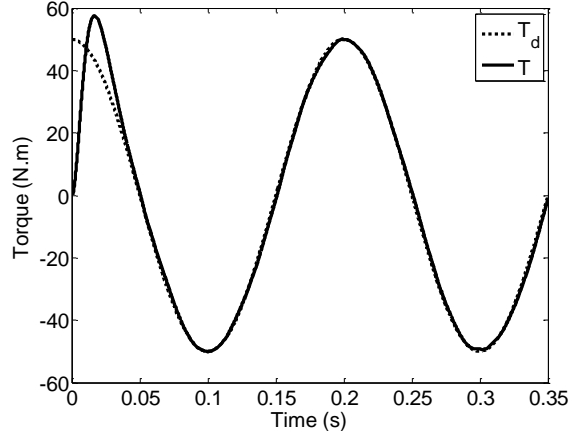

(b) With parameter uncertainty

Figure 8. Response of the integral backstepping-based control system against sinusoidal reference input for $f_{d}=5 \mathrm{~Hz}$

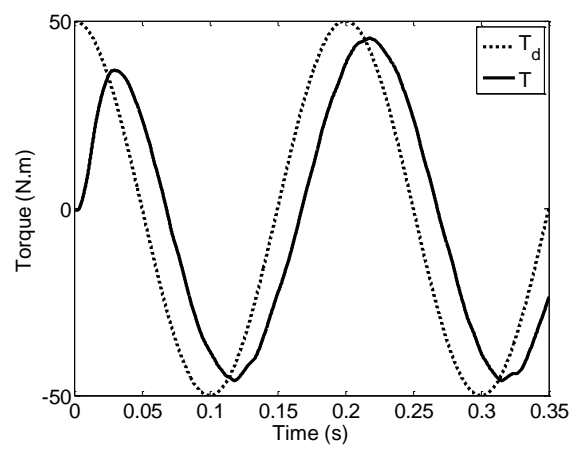

(a) Without parameter uncertainty

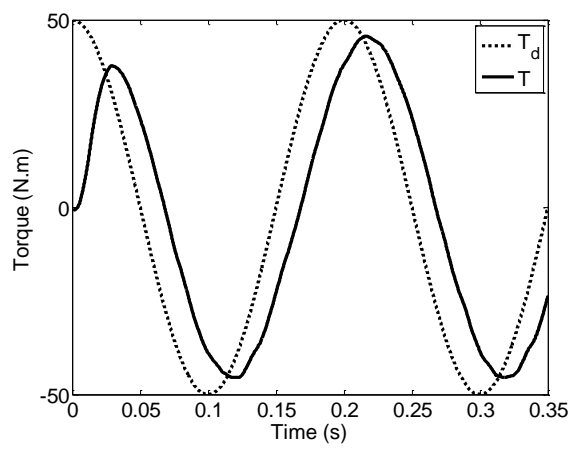

(b) With parameter uncertainty

Figure 9. Response of the PID- based control system against sinusoidal reference input for $f_{d}=5 \mathrm{~Hz}$

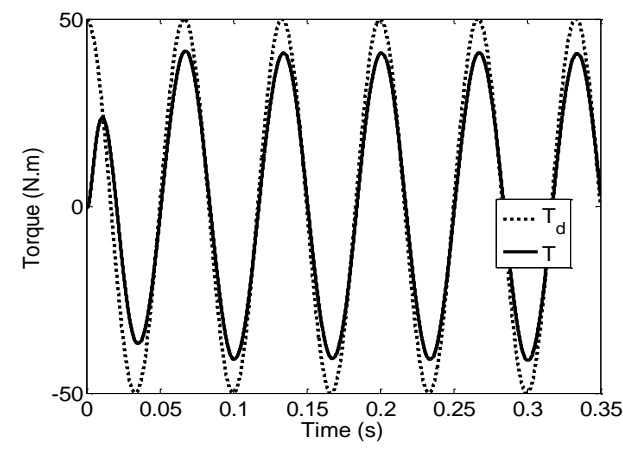

(a) Without parameter uncertainty

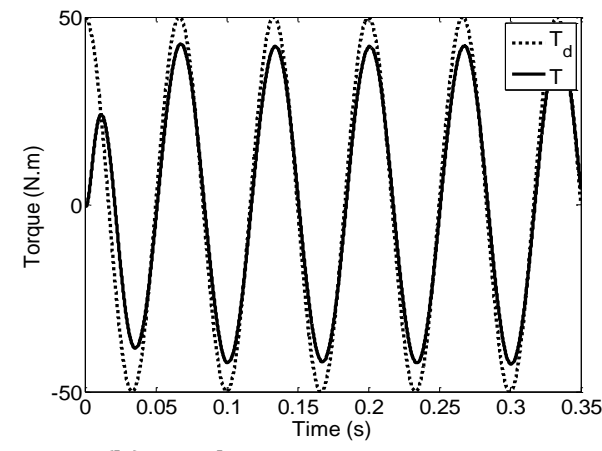

(b) With parameter uncertainty

Figure 10. Response of the integral backstepping-based control system against sinusoidal reference input for $f_{d}=15 \mathrm{~Hz}$ 
B. Özkan / Dynamic Modeling and Control of a Hydraulic Fin Loading System Using Integral Backstepping Method

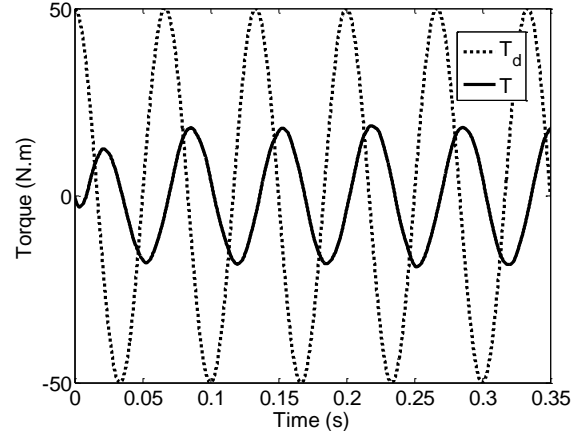

(a) Without parameter uncertainty

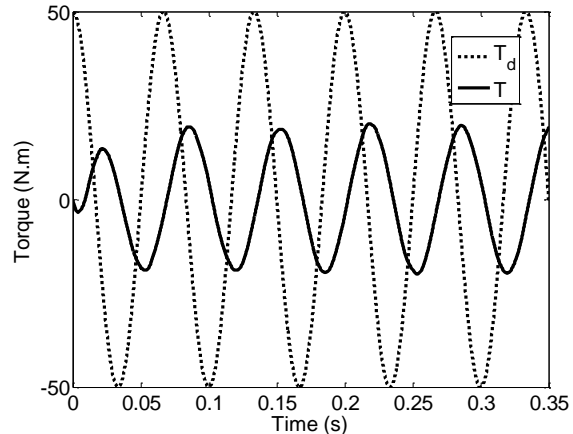

(b) With parameter uncertainty

Figure 11. Response of the PID- based control system against sinusoidal reference input for $f_{d}=15 \mathrm{~Hz}$

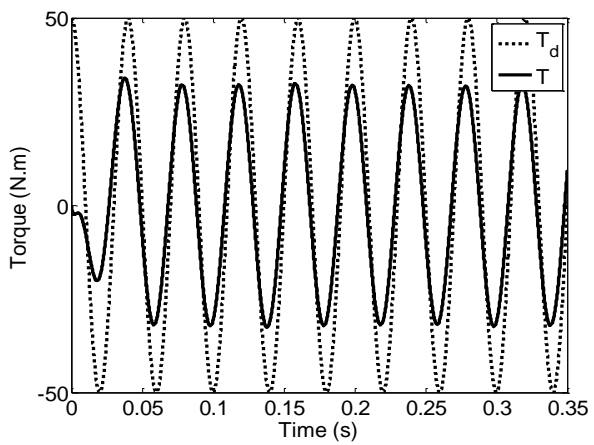

(a) Without parameter uncertainty

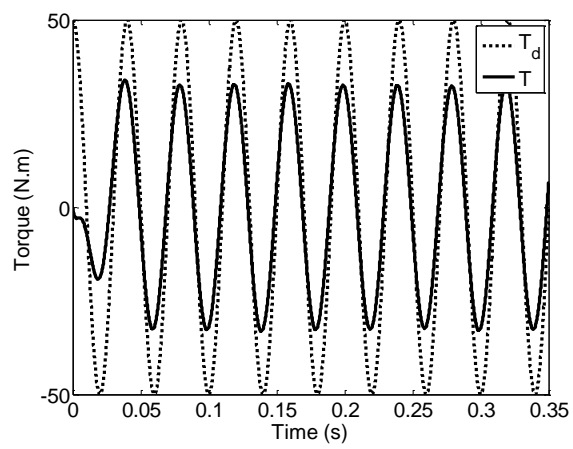

(b) With parameter uncertainty

Figure 12. Response of the integral backstepping-based control system against sinusoidal reference input for $f_{d}=25 \mathrm{~Hz}$

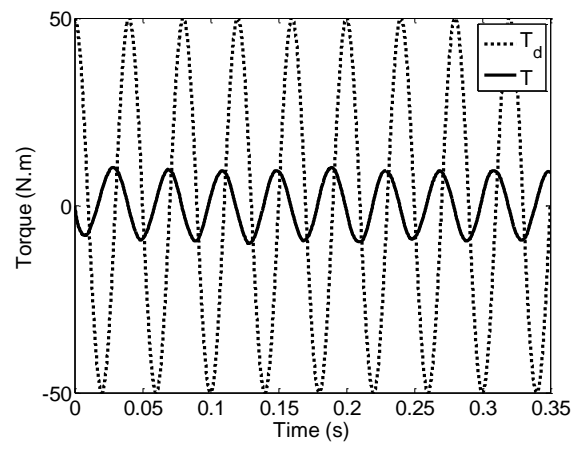

(a) Without parameter uncertainty

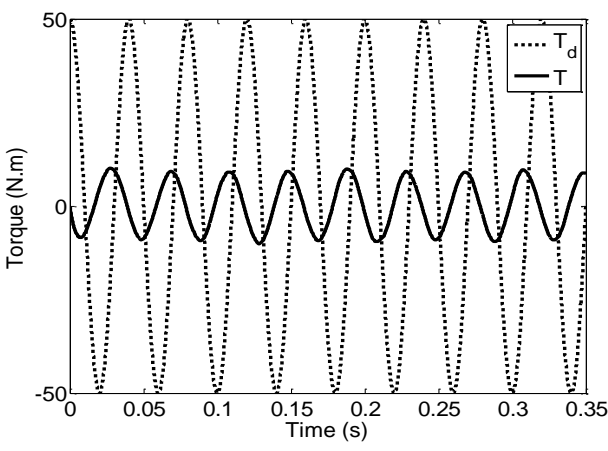

(b) With parameter uncertainty

Figure 13. Response of the PID- based control system against sinusoidal reference input for $f_{d}=25 \mathrm{~Hz}$ 
B. Özkan / Dynamic Modeling and Control of a Hydraulic Fin Loading System Using Integral Backstepping Method

Table 2. Results obtained from the relevant computer simulations for step reference input with $f_{d}=5 \mathrm{~Hz}$

\begin{tabular}{ccccc}
\hline Control System & Parameter & Maximum & Phase & \multirow{2}{*}{ ISE } \\
& Conditions & Overshoot $\left({ }^{\circ}\right)$ & Difference $\left(^{\circ}\right)$ & \\
Backstepping-based & Nominal & 14.487 & 0 & $1.987 \times 10^{5}$ \\
& Uncertain & 16.324 & 0 & $2.104 \times 10^{5}$ \\
\multirow{2}{*}{ PID-based } & Nominal & 1.799 & 0 & $7.916 \times 10^{5}$ \\
& Uncertain & 1.546 & 0 & $5.239 \times 10^{5}$ \\
\hline
\end{tabular}

Table 3. Results obtained from the relevant computer simulations for sinusoidal reference input

\begin{tabular}{ccccc}
\hline \multirow{2}{*}{$\begin{array}{c}\text { Control System } \\
\text { Conditions }\end{array}$} & $\begin{array}{c}\text { Input } \\
\text { Frequency } \\
\text { (fd) }(\mathrm{Hz})\end{array}$ & $\begin{array}{c}\text { Phase } \\
\left.\text { Difference }{ }^{\circ}\right)\end{array}$ & ISE \\
& & 5 & 0 & $4.835 \times 105$ \\
Backstepping-based & & 15 & 5.627 & $2.080 \times 106$ \\
& & 25 & 15.659 & $7.916 \times 106$ \\
& & 5 & 0 & $5.232 \times 105$ \\
& Uncertain & 15 & 6.415 & $1.956 \times 106$ \\
& & 25 & 10.824 & $6.953 \times 106$ \\
PID-based & 5 & 32.158 & $1.881 \times 106$ \\
& & 15 & 68.769 & $9.306 \times 106$ \\
& & 25 & 98.015 & $9.887 \times 106$ \\
& & 5 & 33.318 & $1.816 \times 106$ \\
& & 15 & 68.555 & $9.356 \times 106$ \\
& & 25 & 102.242 & $1.009 \times 107$ \\
\hline
\end{tabular}

\section{Discussion and Conclusion}

As seen from the results of the performed computer simulations, it appears that the maximum overshoots attained with the backstepping-based control system are much higher than those with the PID-based control system when the reference input is step input. On the other hand, regarding both step and sinusoidal type reference inputs, the ISE values obtained for the backstepping control are lower than the values with the PID-type control. That is, the torque control system of the hydraulic fin loading system based on the backstepping has a superior tracking capability to the PID-based control scheme. As expected, the ISE quantitities grow when the designated parameter uncertainties are accounted. In this sense, the only exception occurs in the PID-based control system for $f_{d}=5$ Hz. Also, the uncertainty consideration results in lower maximum overshoot for the PID case. Another advantage of the use of the backstepping control in the torque control of the hydraulic fin loading system comes into the picture in the phase difference between the reference input and system output: The backstepping-based control system leads much lower phase difference quantities than those for their PID counterpart. When the input frequency is enlarged from 5 to $25 \mathrm{~Hz}$, the phase difference values grow up, too. Here, the parameter uncertainties cause the phase difference values to increase as well. Actually, the distinctions between the nominal and uncertainty-added situations are not seen clearly on the relevant plots given above. Yet, the data presented in tables clarify this issue.

However, although it provides the designers with a powerful tool robust against moderate-to-high-amplitude fin deflection disturbing effects, the 
implementation of the backstepping technique to the practical applications involves some difficulties. The main issues are the precise acquisition of the moment quantity arising on the fin connecting shaft and taking the successive time derivatives of the reference input and measurement signals without being affected noise. In order to construct a more accurate control system, a convenient state estimator can also be employed along with the backstepping control.

\section{References}

[1] Guo, Q., Sun, P., Yin, J., Yu, T., Jiang, D. 2016. Parametric Adaptive Estimation and Backstepping Control of Electro-Hydraulic Actuator with Decayed Memory Filter, ISA Transactions, Vol. 62, pp. 202-214.

DOI: 10.1016/j.isatra.2016.02.009

[2] Yao, J., Jiao, Z., Yao, B., Shang, Y., Dong, W. 2012. Nonlinear Adaptive Robust Force Control of Hydraulic Load Simulator, Chinese Journal of Aeronautics, Vol. 25, pp. 766-775. DOI: $\quad 10.1016 / S 1000-9361(11)$ 60443-3

[3] Yao, J., Jiao, Z., Yao, B. 2014. Nonlinear Adaptive Robust Backstepping Force Control of Hydraulic Load Simulator: Theory and Experiments, Journal of Mechanical Science and Technology, Vol. 28, No. 4, pp. 1499-1507. DOI: $10.1007 / s 12206-$ 014-0137-z

[4] Campos, J., Lewis, F. L., Davis, L., Ikegana, S. 2000. Backstepping Based Fuzzy Logic Control of Active Vehicle Suspension Systems. American Control Conference, Chicago, Illinois, USA, 4030-1035.

[5] Ba, D. X., Ahn, K. K., Truong, D. Q., Park, H. G. 2016. Integrated Modelbased Backstepping Control for an Electro-Hydraulic System,
International Journal of Precision Engineering and Manufacturing, Vol. 17, No. 5, pp. 565-577. DOI: 10.1007/s12541-016-0069-x

[6] Won, D., Kim, W. 2015. Disturbance Observer based Backstepping for Position Control of Electrohydraulic Systems, International Journal of Control, Automation, and Systems, Vol. 13, No. 2, pp. 488493.

DOI: 0.1007/s12555-013-0396-y

[7] Guo, K., Wei, J., Fang, J., Feng, R., Wang, X. 2015. Position Tracking Control of Electro-Hydraulic Single-Rod Actuator Based on Extended Disturbance Observer, Mechatronics, Vol. 27, pp. 47-56. DOI: 10.1016/j.mechatronics.2015. 02.003

[8] Wang, C., Jiao, Z., Wu, S, Shang, Y. 2014. A Practical Nonlinear Robust Control Approach of ElectroHydraulic Load Simulator, Chinese Journal of Aeronautics, Vol. 27, No. 3, pp. 735-744. DOI: $10.1016 /$ j.cja.2014.04.011

[9] Wang, X., Wang, S., W., Zhao, P. 2012. Adaptive Fuzzy Torque Control of Passive Torque Servo Systems Based on Small Gain Theorem and Input-to-state Stability, Chinese Journal of Aeronautics, Vol. 25, pp. 906-916. DOI: $\quad 10.1016 / S 1000$ 9361(11)60461-5

[10] Yao, J., Jiao, Z., Yao, B. 2012. Robust Control for Static Loading of Electro-hydraulic Load Simulator with Friction Compensation, Chinese Journal of Aeronautics, Vol. 25, pp. 954-962. DOI: 10.1016/S1000-9361(11)60467-6

[11] Liu, R. 1998. Nonlinear Control of Electro-Hydraulic Servosystems: Theory and Experiment. University of Illinois at Urbana Champaign, MSc. Thesis, USA. 
B. Özkan / Dynamic Modeling and Control of a Hydraulic Fin Loading System Using Integral Backstepping Method

[12] Härkegård, O. 2003. Backstepping and Control Allocation with Applications to Flight Control. Linköping University, PhD. Dissertation, 231p, Sweden.

[13] Aguiar, A. P., Hespanha, J. P., Kokotović, P. V. 2004. Pathfollowing for Non-minimum Phase System Removes Performance Limitations. Proceeding of the Center for Control Engineering and Computation, University of California, Santa Barbara, USA.

[14] Menon, P. K., Ohlmeyer, E. J. 2004. Computer-aided Synthesis of Nonlinear Autopilots for Missiles, Nonlinear Studies, Vol. 11, No. 2, pp. 173-198.

[15] Özkan, B. 2009. Dynamic Modeling and Control of a Hydraulic Fin Loading System Using Backstepping Method, 5th Ankara International Aerospace Conference, Middle East Technical University, Ankara, Turkey.

[16] Ercan, Y. 1994. Fluid Power Control Theory (in Turkish), Gazi University Publication, Ankara, Turkey, 236p.

[17] Ogata, K. 1990. Modern Control Engineering, Prentice-Hall International Editions, Second Edition, USA, 963p.

[18] Joseph, A., Geetha, S. 2007. Application of Backstepping for the Control of Launch Vehicle, IE(I) Journal-AS, Vol. 8, pp. 13-19.

[19] Tsai, F. K., Lin, J. S. 2003. Backstepping Control Design of 360-Degree Inverted Pendulum Systems, 2003 Automatic Control Conference, Taoyuan, Taiwan, 138-143.

[20] Özkan, B. 2005. Dynamic Modeling, Guidance, and Control of Homing Missiles, PhD. Dissertation, Middle East Technical University, 236p, Ankara, Turkey, 2005.
[21] Kealy, T., O'Dwyer, A. 2003. Analytical ISE Calculation and Optimum Control System Design, Irish Signals and Systems Conference, University of Limerick, Ireland. 